\title{
Meaning and Identity Creation in the Culture of Hollandaise Textile Use Among the Igbo of Southeastern Nigeria
}

\author{
Ifeanyi E. Arua, $\mathrm{PhD}$ \\ Department of English, Obafemi Awolowo University, Ile-Ife
}

\begin{abstract}
This paper analyses the names given to vlisco hollandaise fabric designs imported from Helmond, Netherlands by the Igbo suppliers in Nigeria. These names are used to convey social and cultural meanings which could appeal to the sensibilities of prospective buyers who are predominantly women in Igbo society. Data for the study were gathered through interviews of selected suppliers and buyers in south eastern Nigeria. Applying Cognitive Semantic framework, the study examines the naming patterns of the fabrics and their social and cultural meanings. The study shows that the names reflect natural phenomena that are peculiar to the Igbo experiences. They help both the suppliers and the end users to create various identities that enable the suppliers to maximise sales and the women to express themselves socially. These identities align with the different design even when there is no correlation in some cases between the names and the designs.
\end{abstract}

Keywords: Hollandaise, Fabrics, Culture, Name, Igbo women, Identity

DOI: $10.7176 /$ RHSS/11-16-05

Publication date:August $31^{\text {st }} 2021$

\section{Introduction}

Meaning is fluid and sustainable because language users tend to assign meaning to their expressions based on their varied experiences in the world around them. This sustainability leads to linguists' endeavours in proffering different approaches to the study of meaning. Some see meaning as a cognitive, mental or purely denotative practice engaged by humans in order to express their experiences. The various perspectives or approaches to meaning can be streamlined into denotational and connotational types with the connotational aspect going beyond denotational (conventional meaning) to include extra-linguistic senses available in the society. These extra-linguistic components may include socio-economic status, identity/ethnicity, gender, culture and so on. These variables make meaning richer and more encompassing and can be applied to any area of human engagements. This makes it possible to link meaning, textile, identity to the Igbo from the eastern part of Nigeria in describing their behaviour toward existential reality. The Igbo are a group whose clothing preference (women) leans toward tying of wrapper "up and down". This leads to their appreciation of such clothing preferences as Intorica Georges (from India) and Hollandaise textile (from Netherlands) instead of laces. Clothing is anything we put on or add to the naked body to beautify it to enhance our self-esteem and behaviour. The clothing preferences are essential part of their survival be it social, physical or spiritual. The preferences made are determined by both internal and external variables sustained by personality and influenced by needs, beliefs, values, lifestyle, environment and age, among other variables. While lifestyle is affected by living standard (Marshal et al., 2000) and clothing consumption is a means by which lifestyle is expressed, age influences choice of clothing. Youthful exuberances accommodate latest trends in fashion which are ephemeral; the older individuals go for durability, hence the choice of hollandaise materials by Igbo women. The Igbo are found in Abia, Anambra, Ebonyi, Enugu, Benue, Akwa-Ibom, Cross-River, Delta, some parts of Edo and Rivers States of Nigeria. This group of individuals, especially their women identifies more with hollandaise fabrics than any other ethnic groups in Nigeria.

In Nigeria, the different ethnic groups have their different modes of dressing influenced by a lot of factors both internal and external such as culture, status, organisation or group affiliations (peers) and fashion. The symbolic aspect of a group's identity is reflected in their mode of dressing and preferences. External influences may have a hand in the present clothing patterns that follow. Be that as it may, the Yoruba are noted for buba and soro or dansiki with soro overlain with agbada (for men) while the women put on buba and iro or single wrapper, a headgear and iborun (a shoulder length piece of cloth hung down). Kaftan and agbada with cap are associated with Hausa men while their women in public wear a single wrapper with shawl or veil. With reference to Igbo fashion trend, Udechukwu (2017) notes that before colonialism, men went by tying a piece of cloth around their waist to cover their manhood and women put on jigida while the youth and children went about naked. With the arrival of the whitemen, men started wearing shorts and trousers with shirts while the females went about with wrapper and blouse, skirt and blouse or gown. This applies to rules of modesty which graduated to using clothing not to cover nakedness per se but as an advertisement in order to attract attention stressing that clothing is rather for adornment purposes as against covering nakedness according to cultural standards. It is probably at this juncture that hollandaise started featuring prominently in the clothing preferences of Igbo women. Gradually, Igbo men started wearing single plain George material that covers their waist to the knee or 
calf with shirt or singlet while the women went for wrappers and blouse. Igbo women prefer and appreciate the hollandaise material. To them, hollandaise is the king of fabrics and it is durable and not dated or trendy, hence, the name ukpo (a name used by the Igbo in Abia state), meaning main or real material.

According to the Wikipedia, hollandaise is a fabric first produced in 1846 by Pieter Fentener van Vlissingen from the Netherlands. The vlisco fabrics are produced in Helmond, the head office of Vlisco Company. There are different accounts of how the fabrics were introduced in West Africa. One account has it that initially, the fabrics were used for battering during stopovers by the Europeans in West Africa. Since the Dutch were dealing in luxury goods with West Africans as far back as the middle ages, naturally, it seemed logical that they shifted their fabric trading to Africa which seemed to be a welcome idea going by their success. Again, another account which this study identifies with has it that Ghanaian soldiers serving in the Royal Netherlands East Indies Army between 1837 and 1872 returned home with the fabrics for their female relatives. By the $20^{\text {th }}$ century, the trade in the fabric in West and Central Africa was already flourishing and by the 1930s wax hollandaise designs were adapted to Ghanaian local taste. In 1927, the fabrics became popularly known as Guaranteed Dutch vlisco wax or hollandaise wax. This change in name came about as a result of the effect of World War II which caused imitators to spring into action. In 1945 after the war, specifically in 1963, the fabrics shipped to Africa have the text "Guaranteed Dutch wax" to protect authenticity and deter imitators from producing counterfeits. Probably, with the realisation that hollandaise is a material that has actually influenced the African landscape, the company started making one or two core colours designed to reflect on the front and back of the material. The fabric has varied patterns, colours and prints that display African culture. However, it is believed that the fabric is nonAfrican but the naming of the materials is indigenous as explained below:

This fabric that is regarded as African has no Africanese in it but that globalisation and its processes have constructed an image of Africanese. It is the history of the appropriation of knowledge and skills that were invented and produced in Java, became incorporated in Dutch colonial trade routes travels and eventually acquired a new identity in Africa. The fabric has been adapted, appropriated, embraced as a means of self expression to embody what is generally perceived as the quintessential sign of African authenticity. (www.rawmaterialcompany.org, April, 2, 2013).

Again, to capture the attention of the Africans, one of the colours often emphasises natural bubbing effect which lends the fabric its unique, prestigious and vivacious appearance. With the appealing patterns and unique colours, everyone discovers her individual taste, preference and personality in the fabric. Hollandaise has a collection of shades - green, yellow, blue, red, wine, orange and so on available in two yards (yard), four yards, six yards, $12 \mathrm{yds}$.

Any piece of language used in communication symbolises interaction between the users and an entity as language cannot exist in a vacuum. In this way, language helps the suppliers to actualise the goal of naming fabrics and positions them to make a lot of gains from the exercise. Due to the regard accorded to hollandaise, names are given as labels to hike the prices given to the materials. These names portray the aesthetics, status and identification of the materials which automatically confer same attributes thereby enhancing the personality of the user within that environment. The continued placement of importance on hollandaise through the device of names given has legitimised its superiority over other fabrics, hence the interest in examining the meaning and identity attached to the fabric among the Igbo of Southeastern Nigeria.

People give names for various reasons and underlining most names is the identity construct. Naming fabrics gives them identity transferable to the users. In addition, everything in our social system has the potential to mean something. Our type of clothing signifies and indicates something about who we are which is basic for social organisation of culture. The identity of the fabrics is linked to the ideology derived from the ideology of the larger society. Based on their knowledge of their society, the names the suppliers use reflect their understanding of the psyche of the women. Based on the above observations, this study therefore, tries to indentify the names the Igbo give to hollandaise fabric designs, discuss the symbolic reflections of the names to the Igbo and the social values attached to the names. Thus, this study forms a nexus that connects onomastics, semantics and culture where names are seen as cultural markers of experiences meaningful to mostly the name givers who must have gone through the experiences that prompted the name(s) and the consumers that identify with the designs.

\section{Literature Review}

Since its introduction in 1846, the vlisco Dutch wax has the heart of Igbo women in its clutches and rarely can one see a real hollandaise being used to sew ordinary dress or long skirt. Hollandaise appeals more to the middle aged women among the Igbo population who embraced this fabric due to the fact that it does not wear off. Rather, the more one washes it, the more the colours are enhanced which probably is as a result of it undergoing 27 production treatments. Apart from the fabrics' durability, vlisco hollandaise thrives on symbolism which 
allows the African women to silently speak out yet remain silent (Wikipedia). This is because, once a design has been produced and shipped out, it is given a name which ties in with shared knowledge and this process cuts across the cultures that use this fabric. Arts (2012), among others, explains this with examples from Ghana such as "come to my bedroom wearing your slippers" and "Kofi Annan's brain" which induces women to go for the materials. Two sets of critics, pro and anti have made their comments with respect to the fabric. Arts (pro group) cites Akinwumi's (2008) 'African Print "Hoax" views relating to the company's (vlisco) taking credit for originating African prints and thus misleading customers that the fabrics are authentic African designs. By this comment, Akinwumi canvasses for new African aesthetics based on the use of local fabrics such as kente, adire, aso oke and bogolanfini. Akinwumi hopes that his suggestion will ginger government and other stakeholders to look inward for sustainable development. In reaction Akinwumi, Arts draws our attention to the fact that fashion is cyclic and ephemeral. This implies that as years roll by, the tendency of Africans taking charge of the fabric design is possible.

Clothing preferences have always and everywhere been situated to implicitly legitimise existing social power structure in relation to the existence of a group. The introduction of hollandaise in Africa has helped the Igbo women to project the ideology of we also belong. This supports Rabine (2009) who sees dressing as a social action while examining the outfit of Senegal and Malian first Presidents who opted for traditional African dresses. This is recognised as a means of communicating identity, thus suggesting that what we wear has a link with the image we try to project. This reflects the intuitive idea that appearance conveys information about the behaviour of individuals in addition to class, level of achievement with an implicit power control. Apart from the non-verbal aspect, the names given to the fabric designs can segregate and function to indicate the in-group from the out-group. The names are not just mere words, they reflect identities which can be used to reflect the structure of any language and the culture of any group (Essien, 2004).

Tiggemann and Andrew (2012) applying objectification theory examine the effects of clothing on selfperceptions of state self-objectification, state body shame, state body dissatisfaction, and negative mood. The subjects were instructed to imagine what they would be seeing, feeling, and thinking in scenarios (the experimenting involves thinking and wearing a bathing suit in public, in a dressing room). The researchers demonstrate how the power of thought about clothing affects our self-perceptions. Similarly, Adam and Galinsky (2012) using enclothed cognition framework, which explains that dress affects wearers due to the symbolic meaning of the dress and the physical experience of wearing that dress item demonstrate that when clothing has symbolic meaning for the wearer, it also affects the wearer's behaviour. First, the researchers establish that a white lab coat was linked with attributes related to attentiveness and carefulness. They experimented with three groups of people, one group wore a white lab coat depicted as a painter's coat and another group wore the same lab coat which was described as a medical doctor's lab coat. A third group saw, but did not wear, a lab coat described as a medical doctor's lab coat. Participants then performed an experimental task that required selective attention. The group that wore the coat described as a medical doctor's lab coat outperformed both of the other two groups. The study concludes that cultural signification of a dress which is salient within the context (where the cloth is worn and the meaning is clear) of use impact behaviour.

Guy and Banim (2000) focus on how clothing is used as a means of self presentation in everyday life using undergraduates and professional women of several age differentials. They employ three strategies to meet their research objective of investigating women's relationships to their clothing: a personal account, a clothing diary, and a wardrobe interview. The personal account was a written or tape recorded response to the question "what clothing means to me." The clothing diary was a daily log kept for two weeks. The wardrobe interview was centered on participants' current collection of clothing. Three different views were identified with respect to self relative to the women's clothing (1) "the woman I want to be" responses revealed that the women used clothing to formulate positive self-projections. Best items of clothing were basic in bridging the gap between "self as you would like it to be" and the image actually achieved with the clothing. (2)The responses to "the woman I fear I could be" reflect experiences where clothing had failed to achieve a desired look or resulted in a negative selfpresentation. The fear here relates to choosing to wear clothing with unintentional effects such as revealing parts of the body that were unflattering or losing the ability to know how to convey a positive image via dressing. (3)The responses to "the woman I am most of the time" comprise comments that convey that the women had an on-going "relationship with clothes dynamic and that the main source of enjoyment was to use clothes to realize different aspects of themselves" (p. 321).

Ogle et al. (2013), observe in their experiment that a lack of fit between themselves and the clothing styles made available was the main reason their participants were disappointed by the maternity clothing offered through the marketplace. This links the fact that what people know about themselves affect the type clothing they select and purchase. Sirgy (1982) proffers self-image product-image congruity theory to explain the process of how people apply ideas about the self to their purchasing. The theory assumes that products are connected to certain images through marketing and branding. The basis of the theory is that products people are moved to buy are certain products with images that match or are symbolic of how they see themselves or with how they would 
like to be. People also avoid those products that are not in synchrony with either of these self-images.

Rhee and Johnson (2012) are able to relate the self-image product-image congruity relationship with male and female adolescents through investigating adolescents' purchase and use of clothing brands. Participants specify that their preferred clothing brand are those synonymous with their actual self (those that reflect who I $\mathrm{am}$ ), followed by their social self (that which reflects who I want others to think I am), and their desired self (the brand that reflects who I want to be). Earlier, Banister and Hogg (2004) conduct group interviews with adult consumers in their bid to investigate the idea that consumers reject or avoid products with negative symbolic meanings. Their participants agree that clothing items vary in their symbolisms and meaning depending on the interpreter and that the consumers are more worried and conscious with avoiding buying products with negative symbolic images than with products that embed a positive image.

\section{Theoretical Framework}

This study applies the theory of cognitive semantics which considers meaning as a cognitive endeavour that relates language, meaning and cognition (Allwoods and Gardenfors, 1999: iv). Meaning is associated with expressions arising from mental activities and resulting in mental entities (Gardenfors, 1999). Saeed (2003) acknowledges that cognitive semantics recognises that linguistic knowledge is an aspect of general cognition implying that linguistic knowledge is part of the experiential knowledge basic to meaning production and reception. This shows that meaning-making is part of the general cognitive function of the human brain, a functional approach to language study. Again, as a multidisciplinary perspective on language, cognitive semantics describes language incorporating culture and physiological views applying sociological and anthropological distinctions plus the experiences and contexts (pragmatics) to determine meaning of expressions. Thus, this approach goes beyond the formal meaning of words. Newman (1996: ix), cited in Imran and Hashim (2009), summarises the theoretical assumptions of the cognitive linguistics fundamentals as follows:

a. There are important links between linguistic structure and human cognition, making it imperative to acknowledge the role of human cognition and human experience in motivating and explicating linguistic structure;

b. A language community imposes its own categorisations upon the entities which constitute reality and such categorizations may differ considerably from one language community to another;

c. Most of the categories relevant to linguistics are viewed as having central and less central members rather than being criterially defined;

d. Where the meaning of a form needs to be elaborated, then a larger context or 'frame' [domain] needs to be invoked in order to properly describe the meaning.

The names given to the fabrics and their nuanced implications are beyond the normal meaning of the various words and these borders on subjective use of language. Therefore, applying cognitive semantics, will enable us to relate human cognition to human experiences interpreting the meaning of the names of the fabrics and where possible, a larger context (society's ideologies) is evoked of which the name giver is a member in elaborating the meaning of the various labels given to the fabrics.

\section{Methodology}

This study makes use of primary and secondary sources of data. The data for the study were gathered from interviews of selected suppliers and buyers in Southeastern Nigeria. The data comprise 27 designs and names of vlisco hollandaise by the suppliers who are dealers in the fabric. The choice of the selected designs is prompted by the fact that these designs are commonly available and sought after hollandaise fabrics. The names are categorised based on Igbo/English divide. The names are then subjected to analysis using insights from cognitive semantics which help us apply a more encompassing approach to describing meaning behind the suppliers' use of the names which are symbolic to the women. For convenience, the first figure will have three designs while the rest will be in pairs except where it is not convenient.

\section{Data Analysis and Discussion}

Humans do not use words without intentions explicit or implicit and the meaning of words can be cognitive, logical with content sense, be based on association or conceptual structures. Again, the interpretations given to the different designs of the fabric on the part of the name giver reflect the culture of the individual arising from the individual's experiences. On the part of the patrons is the fact that people maintain or buy different designs due to motivation and behaviour in choosing between alternatives to achieve certain goals (Cole, 2004). Motivation is an internal force that is activated by negative or positive factors that lead to behavioural change depending on socio-economic and background of individuals. Therefore, clothing choices can be used to infer a personality gauge. 


\subsection{Igbo Appellations for the Fabric Designs}

Under this category are 1) nkpuru oka, 2) ocheze 3) kpịrịkịịi azu, 4) okoso, 5) okosisi, 6) kịrịkirị star 7) ngbolodi, 8) oso ndi owe ndị. The names under this category are Igbo in origin with the exception of kịịkirị star which is code mixed word.

Figure 4.1a:Nkpụrụ ọka (first from left), Ocheze (middle) and Nkpịịikpị azụ (last)

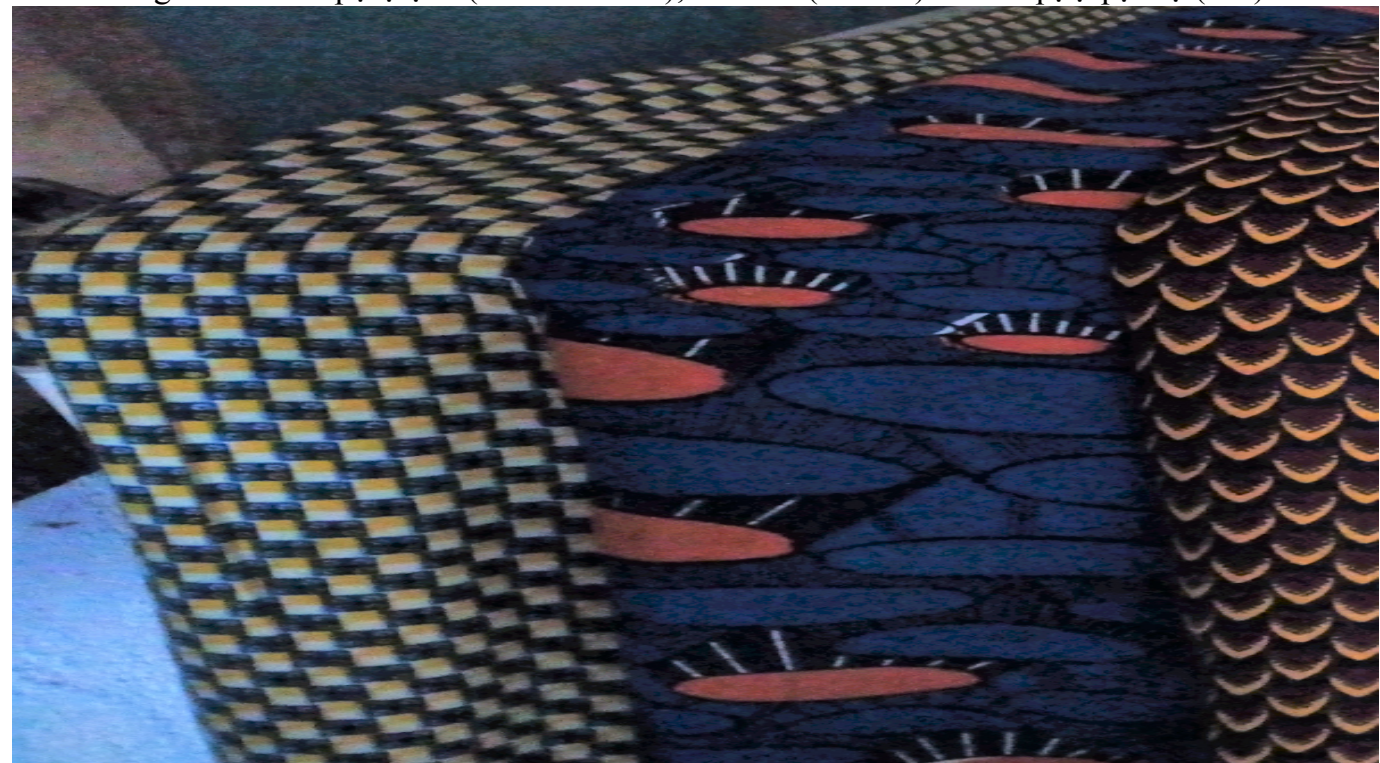

In figure 4.1a, the first is Nkpuruoka which is patterned after the way corn is arranged on the corn cob. Corn is an important cereal used to prepare several dishes and having enough of it is an indication of a well stocked up barn, a protection against famine. So the design is a reminder to plan ahead especially in an under-developed society with inherent incapacity for growth and development. Also, it represents fruitfulness and multiplicity, as one seed when planted yields a thousand seeds more. Ocheze (middle) means royal stool and the design does probably resemble the shape of the royal stool obtained in the olden days when such was introduced by the colonial masters. By implication, the design signifies that anyone that has such actually belongs to the royalty socially. The third design is kpirikpiri azu. The English equivalence of the name is fish scales, a pictura resembling the scales in some fishes. As the scales are a protective mechanism that protects the fish from direct attack, so also is having such a fabric implying that one acquires a protective weapon that indicates that one is not part of the dregs of the society.

Figure $4.1 b$

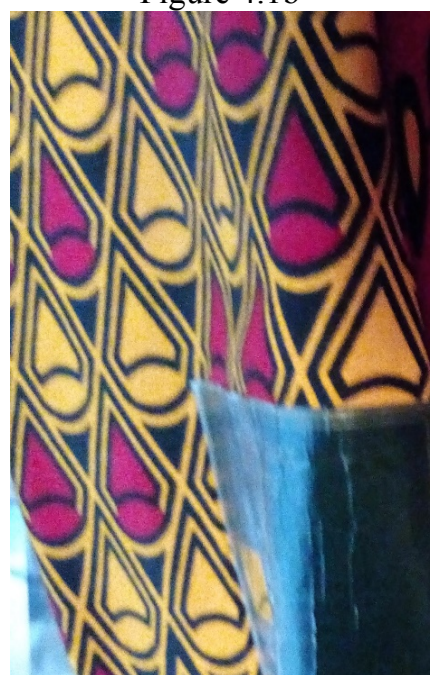

Okoso in figure $4.1 \mathrm{~b}$ is a metal instrument used by children in the traditional set-up as an outdoor game to engage themselves just like what football is used in recent times. It is part of the socialisation process where kids get to know their age mates and form enduring relationships that could last a life time. This design is reminiscence of those formative years. Again, one can be described as okoso which implies that the person is a good dancer just as the okoso which sways and rotates simultaneously on its pointed end from right to left while twisting. 
Figure 4.1c (1)

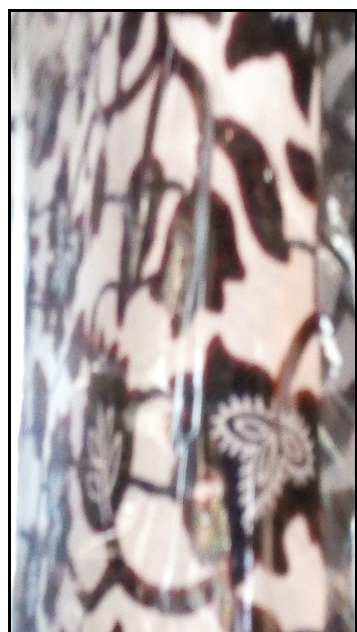

Figure 4.1c (1) is Okosisi which means the big iroko tree, a hardwood from several trees of the genus chlorophora. This design has no tree trunk but smaller stems with flowers which indicate that it is the name giver's intention that is being reflected probably to find ready market for the design. As the iroko is a hardwood rugged for upholstery so is the design to the buyer. Figure 4.1c (2) is referred to as kirịịi star. It has large stars surrounded by a constellation of small stars at specific positions within the fabric. The stars are a reminder of the firmament and pentagons (five pointed stars) which symbolise popularity, success and a mark of quality. As the stars are linked with the sky, so in manner of speaking, the sky is not the limit. One can aspire to be much more if one is able to buy the design.

Figure 4.1d (1)

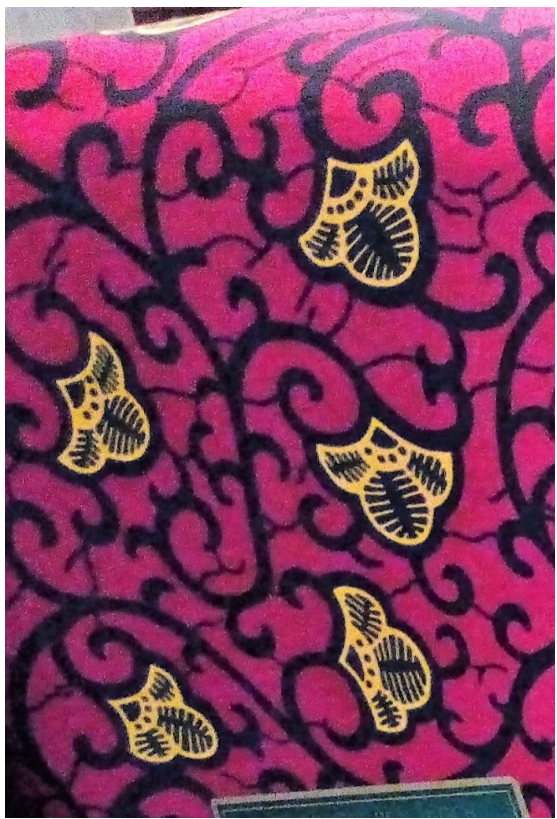

Figure 4.1d (2)

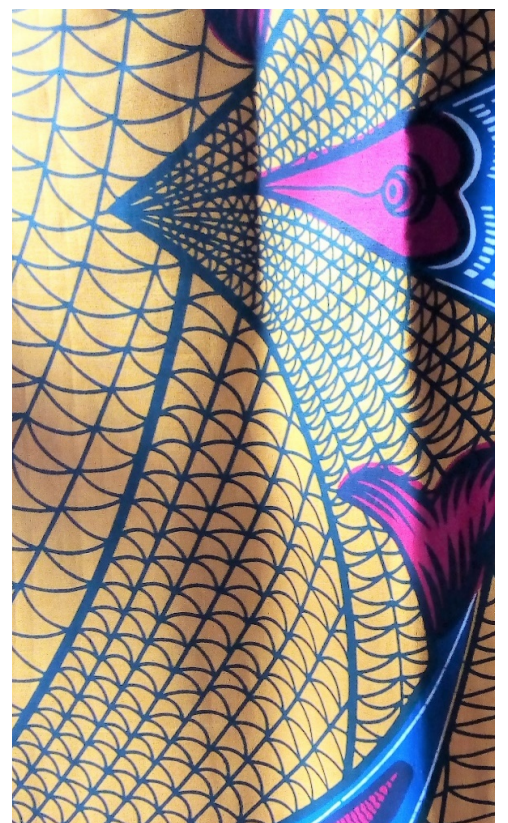

Figure 4.1d (1) is Ngbolodi known as water leaf, an herbaceous plant in West Africa commonly found in the south of Nigeria. In Yoruba, it is called gbure and in Edo it is referred to as ebe dondon. Around the world, it is known as Ceylon spinach, Florida spinach, Philippine spinach, Surinam purslane and cariru. In Nigeria, it is undervalued and underrated leaf that grows during the raining season or in riverside areas. Though underrated and undervalued, it has a lot of nutrients such as vitamins, crude fibre, and lipids among others. These nutrients make the leaf highly medicinal as it improves blood cells; promote healthy heart, eases digestion among others. The design bears a resemblance to the plant with coiled roots. The root of the plant implies going back to the basics, linking up with the kindred for no one is an island and this emphasises the Igbo communal life. Giving the design such name is to bring it to limelight considering the beneficial properties of the leaf which ultimately are transferred to the user. The next, 4.1d(2) is Oso ndi owe ndi which literally means good for others, bad for others or idiomatically, one person's meat is another person's poison. This may emphasise class differences as 
the fabric may be associated with the 'good' and for classy women. The name may also, border on jealousy and has no resemblance with the design. This illustrates traders's bid to bring to limelight some fabric designs just to make them easy to market and women who crave for popularity go for them. The name given to this design emphasises jealousy and it will not be surprising that some women buy this design in order to frustrate other women or to show off.

\subsection{English Appellations for the Fabric Designs}

English appellations include $A B C$, Bible and star, bow and tie, bulb, broken bottles, bullets, butterfly, dice, English gold, fish, heavy rain, iron gate, key, leaf, one thousand blocks, opener, ruler and sugar cane.

Figure 4.2a (1)

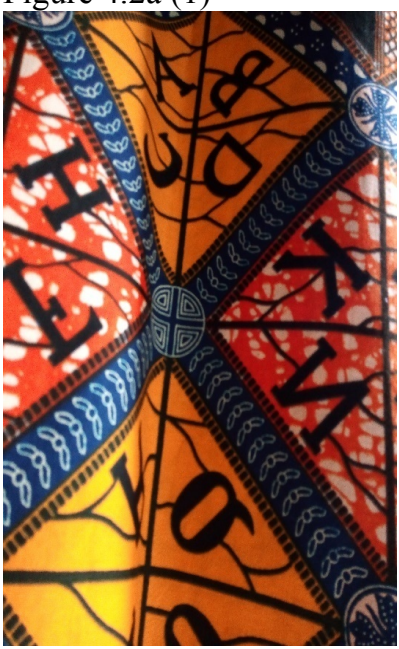

Figure $4.2 \mathrm{a}(2)$

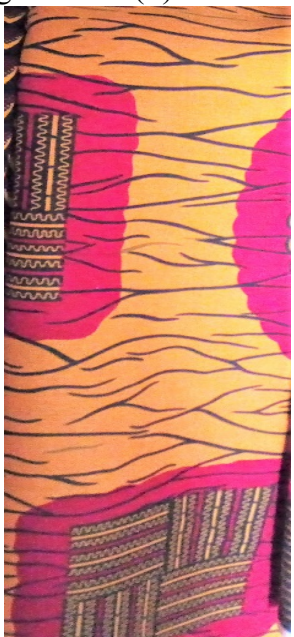

Figure 4.2a (1) is named $A B C$ which is a design that mirrors its name as it has the letters of the alphabet written all over which is a reminder of the letters of English language through whose presence hollandaise fabrics were introduced to the people and by implication it indicates literacy. Figure 4.2a (2), Bible and star is a design that has the drawing of something that is square-like in shape resembling a book which is taken to represent the bible, a holy/sacred book and the star is related to the Star of David heralding an important event that is linked to the birth of Jesus. Having a design like this signals closeness to the Christian teachings which indicates spirituality.

Figure 4.2c (1)

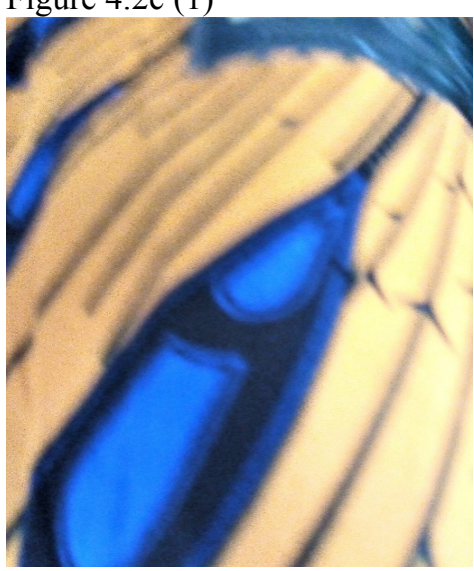

Figure 4.2c (2)

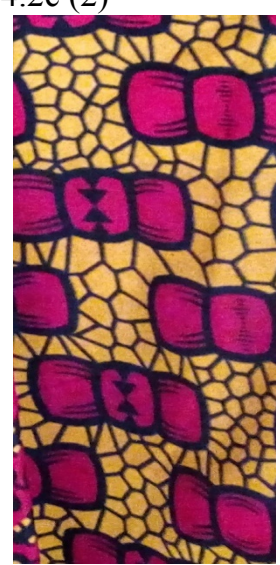

Figure 4.2c (1) is labelled Bulb which is a tube-like design that signals urbanity, civilisation because with the bulb one of the collocates of electricity is implied together with all that is affiliated with it such as industrialisation, technology and so on. Bow and tie which is the design represented in figure 4.2c (2) has the design of neck-tie which indicates class especially when it complements a suit. 
Figure $4.2 \mathrm{~d}(1)$

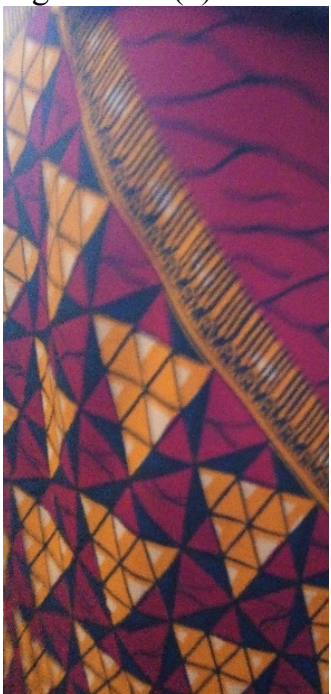

Figure $4.2 \mathrm{~d}(1)$

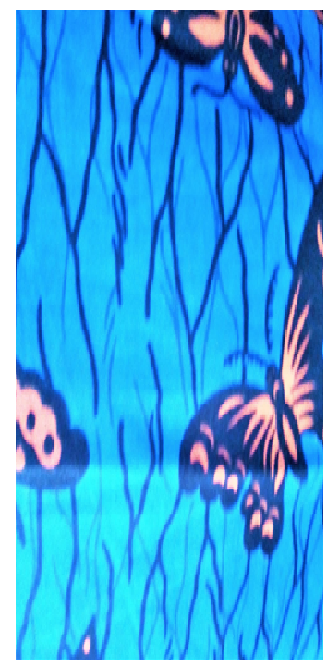

Broken bottles in figure 4.2d (1) is pictorial that bears no resemblance to the design's name; however, the design has small triangles within larger triangles representing pieces of broken bottles. The name is probably given for selective identification. In Igbo, there is a saying that a broken bottle cannot be mended and the broken bottle can refer to relationship, issues that have gone beyond repair. Therefore, broken bottles refer to situations beyond control signaling an "I-don't-care attitude" to consequences arising from any issues. Butterfly in figure $4.2 \mathrm{~d}$ (2) is a design that bears a resemblance to the name given to the fabric. The legendary Mohammed Ali devised a strategy, the dancing butterfly, which he used during his boxing career. The implication of this to Mohammed applies here too. As it is hard to hit a dancing butterfly so it is for the owner to be a target for any assault.

Figure $4.2 \mathrm{e}(1)$

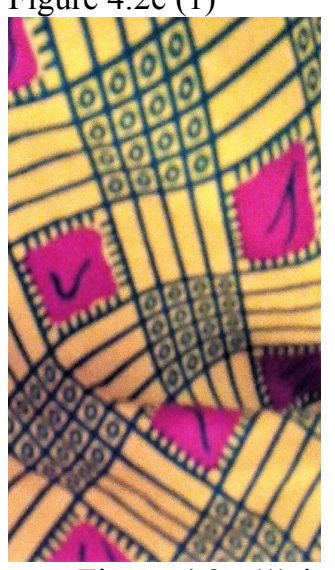

Figure 4.2e (2)

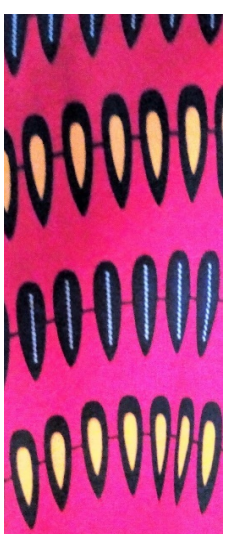

Figure 4.2e (1) is a design referred to as the Dice used to play an indoor game, Ludo. This game is about survival skills, how to manipulate situations and to know when to move away from harm or wait for the opponent(s) to expose itself. As the dice is rolled on board, whatever number that turns up determines the player's survival, so does the design which indicates a test of individual's ability to even up in life. Bullet in figure 4.2e (2) has a cylindrical shape with a tapering and rounded ends resembling pellets. This implies that with the pellets (bullets), there is no stopping of the owner who can brood no hostility or rival. This design and oso ndi owe ndi border on jealousy. Since bullets are meant for the enemy (human or animal), the name intends to silence detractors. 

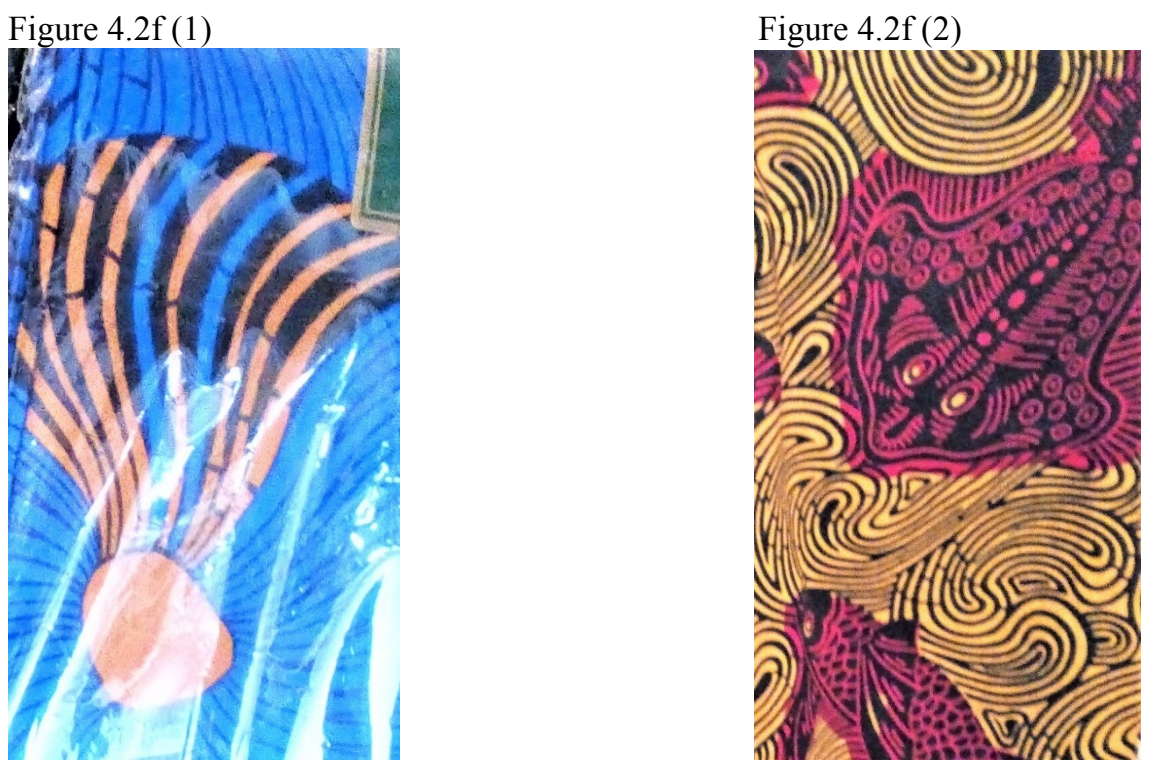

The picture in figure 4.2f (1) is labelled English gold and it bears no resemblance to the name given to the design. It is probably a case of an enhancer to help make sales. Fish design has different types of fish on the fabric showing the African especially, Nigeria's aquatic life. Fish in dishes is a sign of or reflects tastiness because fish is more regular in Igbo soup than meat. The fish depicted in the design are species of a particular fish asa in Igbo. This fish reflects prestige, power and beauty. It is used during prestigious ceremonies like celebration of valour and conferment of chieftaincy titles. It is also a symbol of love used by women to signal to their husband that all is well (Okwudishu, 2009). By extension, this design signals love for the husband as well as indicating beauty, power and prestige. Heavy rain has a water bubbles with a pictorial of heavy wind which equals the name. Rain is for fertility and anyone who can cause the rain to fall has power. Iron gate has the design that indicates straight lines crossing each other at the boarder of the fabric. These straight lines are taken to resemble burglary proofs meant for protection. Having such material is a protection against intimidation, insecurity as well as keeping one's social status intact. In Nigeria, we have two seasons (harmattan or dry and rainy seasons). Rain in Heavy rain (represented in figure 4.2g (2)) heralds planting season leading to abundance (especially after the dry season when there are scarcities of some food items) and signals a change in activity. However, when the rain becomes heavy, little or no outdoor activities can done but people will be around the fire place roasting corn while young women engage in airing/drying their melons whenever the rain reduces or letsup. It is basically the month of "where am I going", a waiting period when farms have been weeded and yams staked.

Figure 4.2g (1)

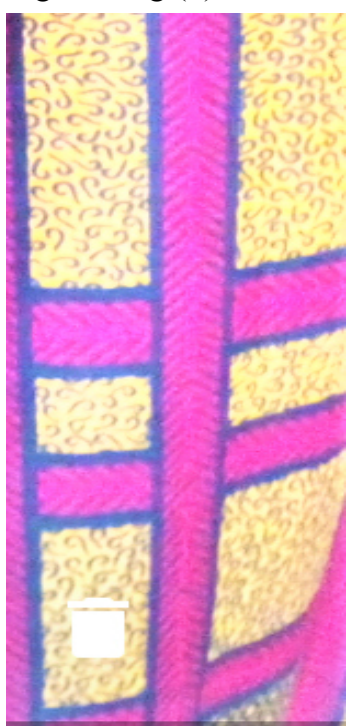

Figure $4.2 \mathrm{~g}(2)$

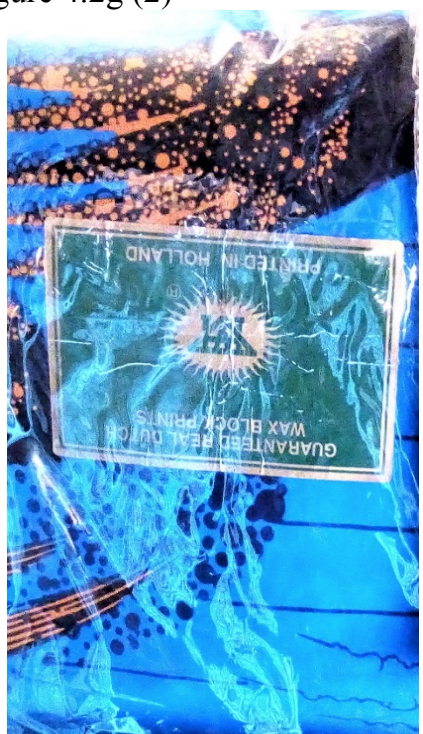

Jumping horse is an agile animal that can be domesticated. It may also convey the image of one who jumps around implying a recalcitrant that needs to be reined, curbed and tamed. An uncontrolled horse may imply eyes that rove without restraint. Key design bears resemblance to the name. Positively, a key opens something. 
Socially, the design keys the wearer to all positive progressive opportunities available

Figure $4.2 \mathrm{~h}(1)$

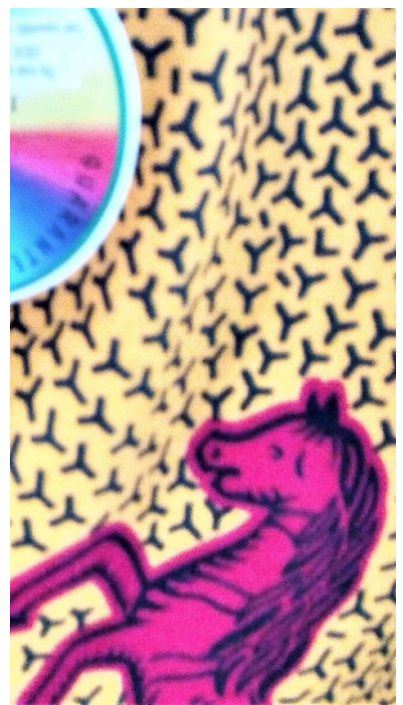

Figure $4.2 \mathrm{~h}(2)$

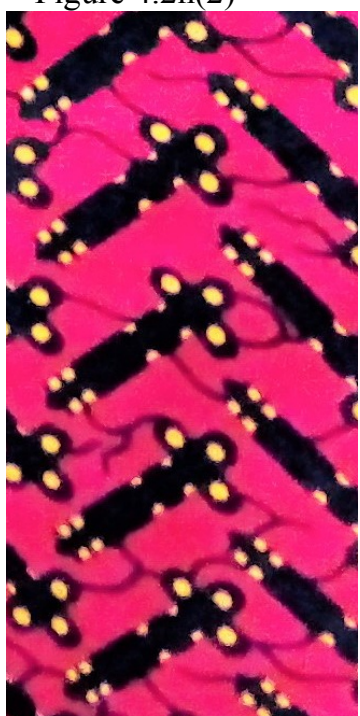

One thousand blocks has rectangular shapes arranged sideways and on top of each other hence, the name. Blocks are associated with houses and corrugated roofs and not thatched ones. The implication is that whoever can build such a house belongs to the upper class and is worthy of recognition. Leaf is indicated in figure 4.2i (2) and going by the postures of the leaf, it is not dry and as such it spells freshness filled with life and very potent.

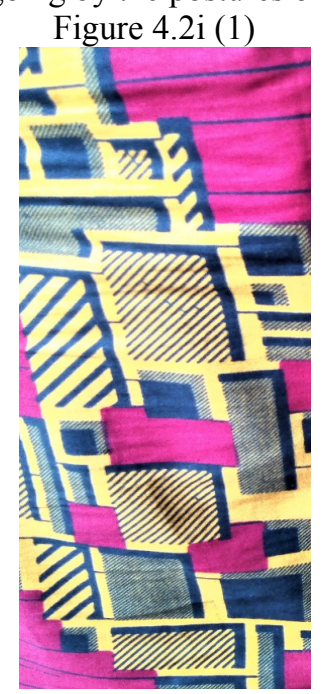
Figure $4.2 \mathrm{i}(2)$

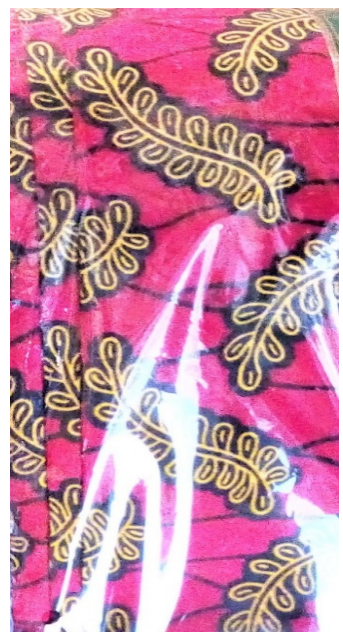

Compared to a dry leaves from a dry tree that is stiff and brittle, fresh leaves as represented by ones on the design, can adapt to the changing times as they can sway this way, that way and stand and maintain their balance. Opener and Ruler are pictured below in figures 4.2j (1) and (2). Opener resembles the opener used in uncorking bottles of wines and therefore, the design infers class. The name can also imply that buying it indicates that one has the instrument to open doors of opportunities socially. Ruler is another design that has broad lines resembling a ruler without calibration but with lines crossing each other. It can be inferred that the social height can be measured with a ruler and possessing such a material means the owner is worthy of recognition. 
Figure 4.2j(1)

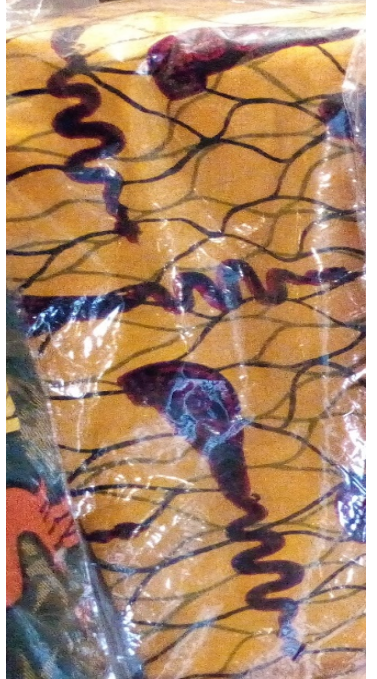

Figure $4.2 \mathrm{j}(2)$

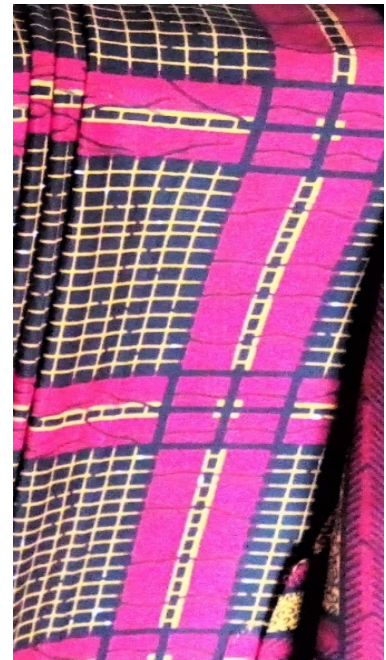

The last to be discussed is the design laballed sugar cane in the figure below. Sugar cane bears a slight resemblance to the actual entitiy/object in the real world as far as the segmented nature of sugar cane is concerned. It is probable that the name stems from the knowledge of the benefits of sugar cane. As a rich source of maple sugar, it is used to prepare dishes, smoothies and has a lot of vitamins, organic salts (calcium, phosphorous, iron), and organic acids and so on. It is probable that these considerations may not have crossed the mind of the name giver. However, some of the health benefits are well known to them such as using it to take care of the teeth, treat jaundice, flu and sore throat. One may be tempted to suggest that the benefits inform the name. Going by the benefits, it seems to be an all purpose elixir and by implication, the fabric design may be regarded as a cure-all material socially.

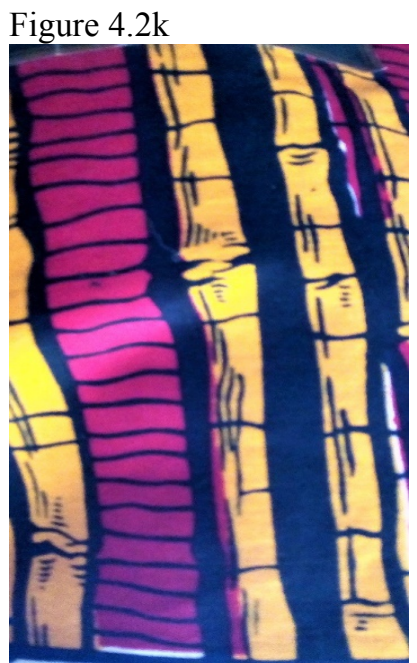

From the discussion, we observe that the names indicate human's connectedness with phenomena found in the environment both living and non-living things. Also, the study illustrates people's identification with positive aspects of life, making the most of the symbiotic relationship to effectively make a living culminating into increase in sales as well as attending to the whims and emotions of women that patronise the traders. It is interesting to point out that almost all these fabric designs are associated with certain ceremonies in Igbo society. Also, there are some age grades, cultural groups, religious associations and vocational groups which have preferences for some of the fabrics. For instance, the Presbyterian Women's Guild uses the mkpuru oka which may represent the Christian injunction "go into the world and multiply" as uniform. The famous annual August Meeting in various Igbo communities where developmental issues that concern each community are discussed uses various fabric designs as uniforms and no two groups within the same community can use the same fabric design as the designs are means of identification.

\section{Conclusion}

From the analysis, the study concludes that identities represented by fabric designs and names are like faces which the individuals using the different designs at different times and situations possess. Identity relates to 
assume roles people fit-in in concurrent situations in a group. One of these identities may be fore-grounded at different times-sometimes contradictory, sometimes interrelated. People's diverse identities constitute the richness and dilemma of their sense of self. Igbo women patronise hollandaise because it is a fabric that is consistent with their self worth and reflects who they want to be in terms of pronouncing their ambition for social mobility. Through the clothing preference the Igbo women have also been able to appropriate the fabric designs as part of their culture through the names given to describe each of them. The names given to the fabric designs are symbolic and reflect the cultural experiences of the women, hence, their identifying and appropriating the fabric into their culture and speaking through them without using voice.

\section{References}

Adam, H. \& Galinsky, A. D. (2012). Enclothed Cognition. Journal of Experimental Social Psychology, 48(4), 918-925.

Allwood, J., \& Gärdenfors, P. (1999) (Eds). Cognitive Semantics: Meaning and Cognition. Amsterdam and Philadelphia: John Benjamins Publishing Company.

Arts, J. (2012) Vlisco (in Dutch) Arnhem:Uitgeverij Wbooks/ArtE2 Press.

Banister, E. \& Hogg, M. (2004). Negative Symbolic Consumption and Consumers' Drive for Self Esteem: The case of the fashion industry. European Journal of Marketing, 38(7), 850-868.

Cole, G. (2004) Personal and Human Resources Management. Surrey: Guildford and King Publication Biddles Ltd.

Essien, O. E. (2004). Naming in Nigeria: An Exploration of the Enterprise among some Ethnic Groups. In Ozomekuri, N. (Ed.), Language and Culture in Nigeria: A festschrift for Okon Essien, Aba: NINLAN, 105-123.

Gärdenfors, P. (1999). Some Tenets of Cognitive Semantics". In Allwood, J. Gärdenfors, P. (1999) (Eds). Cognitive Semantics: Meaning and cognition. Amsterdam/Philadelphia: John Benjamins Publishing Company.

Guy, A. \& Banim, M. (2000). Personal Collections: Women's Clothing Use and Identity. Journal of Gender Studies, 9(3), 313-327.

Marshall, S. C., Jackson, O. H., Stanley, M. S., Kefgan, M. \& Touchie-Sepcht, P. (2000) Individuality in Clothing Selection and Personal Appearance. New Jersey: Prentice Hall.

Okwudishu, A. U. (2009). An analysis of Fish Names in Ogwuta Culture: Implication for the Millennium Development Goals. In Ozo-mekuri, N. (Ed.) Nigerian Languages, Literature, Cultures and Policy 6 Reforms: A Festschrift for Ayo Bamgbose, series No. 6, 353-366.

Ogle, J., Tyner, K. \& Schofield-Tomschin, S. (2013). The Role of Maternity Dress Consumption in Shapingthe Self and Identity during the Liminal Transition of Pregnancy. Journal of Consumer Culture, 13(2), 119139

Rabine, W. L. (2009) Spontaneous Political Photography of Senegal and Mali's First Presidents. Conference Paper on Dress, Popular Culture and Social Action in Africa sponsored by The Graduate School, The Progam of African Studies, The Buffett Center for International and Cooperative Studies and The Department of Anthropology, March 13-14, 2009.

Rhee, J, \& Johnson, KKP. (2012). Investigating Relationships Between Adolescents' Liking for an Apparel Brand and Brand-self Congruency. Young Consumers, 13(1), 74-85.

Saeed, J. (2003). Semantics. Oxford: Blackwell Publishing

Sirgy, M. J. (1982). Self-concept in Consumer Behavior: A Critical Review. Journal of Consumer Research, 9(3), 287-300.

Tiggemann, M, \& Andrew, R. (2012). Clothes Make a Difference: The Role of Self-objectification. Sex Roles, 66(9-10), 646-654.

Tiggemann, M, \& Andrew, R. (2012). Clothes Make a Difference: The Role of Self-objectification. Sex Roles Roles, 66(9-10), 646-654. 